\title{
Caffeine to improve breathing effort of preterm infants at birth: a randomized controlled trial
}

\author{
Janneke Dekker ${ }^{1}$, Stuart B. Hooper ${ }^{2}$, Jeroen J. van Vonderen ${ }^{1}$, Ruben S.G.M. Witlox ${ }^{1}$, Enrico Lopriore ${ }^{1}$ and Arjan B. te Pas ${ }^{1}$
}

BACKGROUND: Caffeine promotes spontaneous breathing by antagonizing adenosine. We assessed the direct effect of caffeine on respiratory effort in preterm infants at birth.

METHODS: Thirty infants of 24-30 weeks of gestation were randomized for receiving caffeine directly after birth in the delivery room (caffeine DR group) or later in the neonatal intensive care unit (control group). Primary outcome was respiratory effort, expressed as minute volume, tidal volumes, respiratory rate, rate of rise to maximum tidal volume, and recruitment breaths at 7-9 min after birth.

RESULTS: After correction for gestational age, minute volumes ((mean \pm SD; $189 \pm 74$ vs. $162 \pm 70 \mathrm{ml} / \mathrm{kg} / \mathrm{min}$; $P<0.05$ ) and tidal volumes ((median (interquartile range (IQR)) $5.2(3.9-6.4)$ vs. $4.4(3.0-5.6) \mathrm{ml} / \mathrm{kg})$ were significantly greater in the caffeine DR group. Although respiratory rates were similar ((mean \pm SD) $35 \pm 10$ vs. $33 \pm 10)$, RoR increased significantly ((median (IQR) 14.3 (11.2-19.8) vs. 11.2 (7.9-15.2) $\mathrm{ml} / \mathrm{kg} / \mathrm{s})$, and more recruitment breaths were observed (13 vs. $9 \%)$.

CONCLUSION: Caffeine increases respiratory effort in preterm infants at birth, but the effect on clinical outcomes needs further investigation.

D uring the transition after birth, lung aeration is pivotal for the changes in respiratory and cardiovascular function that are required for survival $(1,2)$. Although most preterm infants breathe at birth, their respiratory drive is weak and often insufficient to aerate their lungs and establish gas exchange (3-7). To minimize injury, intubation and mechanical ventilation is now avoided, and the focus of respiratory care has shifted to noninvasive ventilation, involving positive pressure support of breathing and/or ventilation via facemask $(6,8)$.

Recent studies have demonstrated that intermittent positive pressure ventilation, applied via mask in infants with insufficient respiratory effort, was often ineffective unless the infant took breaths during intermittent positive pressure ventilation (3). Mask ventilation is often hampered not only by leak but also by obstruction caused by active larynx adduction $(3,4,9)$. Antenatally, active larynx adduction during apnea is needed for lung expansion and lung growth (9), and this pattern of activity might temporarily persist at birth. Logically, the best way to open the larynx is to stimulate spontaneous breathing, which is also likely to be the most gentle and effective way of providing respiratory care without causing injury. Currently, only tactile stimulation is recommended to stimulate breathing (10-12).

Caffeine promotes breathing in infants by antagonizing the suppressive effects of adenosine and is a safe and effective treatment for apneas of prematurity $(13,14)$. When caffeine is given in the first hour after birth, diaphragmatic activity is increased at $5 \mathrm{~min}$ after caffeine administration, which correlates with an increased tidal volume $\left(\mathrm{Vt}_{\mathrm{i}}\right)$ (15). In addition, the need for vasopressors and the incidence of intubation are lower when caffeine is given in the first few hours after birth, compared with that given after $12 \mathrm{~h}$ (16). In addition, the incidence of bronchopulmonary dysplasia was lower when caffeine was given in the first 2 days of life $(17,18)$. Although these studies demonstrated the effects of caffeine in the first days after birth, there is little data on the direct effect of caffeine on respiratory effort or whether gestational age (GA) influences the effect of caffeine. Bairam et al. (19) showed that in 2-5-day-old term lambs $\mathrm{Vt}_{\mathrm{i}}$ increased after a loading dose of caffeine. Kraaijenga et al. (15) confirmed this in 1-4-day-old preterm infants by measuring diaphragmatic activity after caffeine administration (19). Within $5 \mathrm{~min}$ of administration, diaphragmatic activity increases, resulting in a $30 \%$ increase in tidal volumes (15). Higher tidal volumes could potentially lead to greater lung recruitment and improved oxygenation, which can result in an increased respiratory drive (20). We hypothesized that this effect of caffeine can be duplicated when caffeine is administered directly after birth.

We aimed to evaluate the respiratory effort of preterm infants at birth when caffeine was either administered directly after birth in the delivery room or after admittance to the neonatal intensive care unit (NICU).

\section{METHODS}

An unblinded randomized controlled trial was conducted at the Leiden University Medical Center. Preterm infants born between 24 $(0 / 7)$ and $29(6 / 7)$ weeks of gestation were included. We excluded

${ }^{1}$ Division of Neonatology, Department of Pediatrics, Leiden University Medical Center, Leiden, The Netherlands; ${ }^{2}$ The Ritchie Center, MIMR-PHI Institute of Medical Research, Melbourne, Victoria, Australia. Correspondence: Janneke Dekker (j.dekker@lumc.nl) 


\section{Caffeine for breathing at birth $\quad$ Articles}

infants with congenital abnormalities or conditions who might have an adverse effect on breathing or ventilation, including congenital diaphragmatic hernia, tracheoesophageal fistula, or cyanotic heart disease. Infants participating in other trials on respiratory effort were also excluded. Infants were randomized using sequentially numbered sealed envelopes to either receive a loading dose of caffeine base $(10 \mathrm{mg} / \mathrm{kg}$, based on estimated or measured birth weight) at birth in the delivery room (caffeine DR group) or later after arrival in the NICU (control group). Consecutive caffeine base therapy was given in both groups according to the local protocol $(5 \mathrm{mg} / \mathrm{kg}, 24 \mathrm{~h}$ after loading dose). Allocation was stratified by GA $(24(0 / 7)-26(6 / 7)$ or $27(0 / 7)-29(6 / 7)$ weeks) using blocks of 4 . When randomized for caffeine administration in the delivery room, a butterfly needle $(21 \mathrm{G})$ that was prefilled with saline and attached to a saline-filled $5 \mathrm{ml}$ syringe was inserted in the umbilical vein just above the umbilicus after a chlorhexidine swap. Endovascular location of the needle tip was confirmed by flushing in saline and withdrawing blood. A bolus of caffeine was administered within the first $7 \mathrm{~min}$ after birth. After the administration of caffeine, a further $2 \mathrm{ml}$ flush of saline was given.

None of the mothers received general anesthesia or IV narcotics close to delivery. In both groups, standard care was provided in both the delivery room and after arrival in the NICU. A Auckland, New Zealand Neopuff infant T-piece resuscitator (Fisher \& Paykel Healthcare, Auckland, New Zealand) was used for respiratory resuscitation. For stabilization at birth, local resuscitation guidelines were followed, including delayed cord clamping and early start of Continuous Positive Airway Pressure for all infants with a GA below 32 weeks. In addition, a sustained inflation of $15 \mathrm{~s}$ with a pressure of $20 \mathrm{~cm} \mathrm{H}_{2} \mathrm{O}$ was given to apneic and bradycardic infants. A second sustained inflation of $15 \mathrm{~s}$ with a pressure of $25 \mathrm{~cm} \mathrm{H} \mathrm{H}_{2} \mathrm{O}$ was given when infants remained apneic and bradycardic, after which intermittent positive pressure ventilation was started. Intubation was considered when effectiveness of mask ventilation could not be guaranteed or prolonged mask ventilation was needed. Respiratory function monitoring was recorded at birth, which is also standard clinical care in our center to have a direct feedback device for respiratory support. This monitor was used to measure inflation pressures, gas flow, $\mathrm{Vt}_{\mathrm{i}}$, average $\mathrm{MV}$, and average rate of rise to maximum tidal volume (RoR). The monitor utilizes a small (dead space $1 \mathrm{ml}$ ) variable orifice anemometer to measure gas flow in and out of a facemask. This signal was automatically integrated to provide inspired and expired tidal volume. Respiratory function monitoring measurements were collected during the first $10 \mathrm{~min}$ after birth. All signals measured were digitized and recorded at $200 \mathrm{~Hz}$ using the New Life Box physiological recording system (Advanced Life Diagnostics, Weener, Germany) with the Polybench software (Advanced Life Diagnostics, Weener, Germany). The Pulmochart software (Advanced Life Diagnostics) was used for analyzing the recorded data. Oxygenation and heart rates were measured with a Massimo SET pulse oximeter (Masimo corporation, Irvine, CA, USA). The pulse oximetry probe was placed around the ulnar aspect of the infant's right wrist. Fraction of inspired oxygen $\left(\mathrm{FiO}_{2}\right)$ was measured with a Teledyne oxygen analyzer (Teledyne Analytical Instruments, City of Industry, CA, USA) inserted into the inspiratory limb of the Neopuff circuit.

The primary outcome was respiratory effort, expressed as MV of spontaneous breathing at 7-9 min after birth. Also, the inspired tidal volumes $\left(\mathrm{Vt}_{\mathrm{i}}\right)$, respiratory rate, the RoR, and recruitment breaths (\% of tidal volumes $>8 \mathrm{ml} / \mathrm{kg}$ ) were used as parameters of respiratory effort. Maximum fraction of inspired oxygen $\left(\mathrm{FiO}_{2}\right)$, oxygen saturation $\left(\mathrm{SpO}_{2}\right)$, and heart rate at 7-9 min after birth were also measured. Analyses were performed on these outcomes at 7-9 min after birth; as we assumed that caffeine could be administered within the first $7 \mathrm{~min}$ after birth, most infants would be respiratory stable at $7 \mathrm{~min}$, and were transported to the NICU $10 \mathrm{~min}$ after birth.

To observe the direct effect of caffeine, we compared the MV in the minute before (period 0) with that in the minute after (period 1) caffeine administration in the caffeine DR group. The frequency of expiratory holds and panting was also compared, using the definitions previously described by te Pas et al. (21). Basic characteristics of all included infants were collected-GA, birth weight, gender, Apgar score, antenatal use of corticosteroids, mode of delivery, the need for a sustained inflation, and cord $\mathrm{pH}$ and BE. Data were also collected on short-term clinical outcomes as intraventricular hemorrhage, intubation, and need for surfactant administration during the admission on the NICU.

On the basis of the previous studies of Bairam et al. (19) and Kraaijenga et al. (15) that examined the direct effect of caffeine, we calculated that with an $\alpha$ of 0.05 and $\beta$ of $0.8,26$ infants were needed to detect a $150 \mathrm{ml} / \mathrm{kg} / \mathrm{min}$ increase in MV with an SEM of 60 .

The ethical committee of the Leiden University Medical Center approved the study protocol. Parental informed consent was obtained prior to randomization, and in emergency situations with immediate delivery required or when approaching parents for antenatal consent was not considered appropriate, consent was obtained retrospectively as soon as possible after birth.

Statistical analysis was performed with the SPSS software version 23.0 (SPSS, Chicago, Illinois). The parameters of both groups were tested for normality using the Kolmogorov-Smirnov and ShapiroWilkinson test. The caffeine DR group and control group were compared using Student's $t$-test for parametric and the MannWhitney for nonparametric comparisons for continuous variables, and the $\chi^{2}$-test for categorical variables. Results are presented as mean \pm SD for normally distributed values or median (interquartile range) for non-normally distributed values. $P$ values $<0.05$ were considered statistically significant. Reported $P$ values are two-sided. MV was calculated using only tidal volumes recorded without mask leakage, and dividing it by the number of seconds for which data were present. Of all other study parameters, calculations were made based on the available data. Despite randomization of infants, a significant and clinically important baseline imbalance in GA between the two groups was discovered. As a result, we performed a post hoc analysis to adjust the outcome parameters for the GA and examined the relationship between GA and MV together and separately in both groups using the PRISM software (Irvine, CA, USA). Reported results are corrected for GA.

\section{RESULTS}

Between November 2014 and August 2015, 76 eligible infants were born in the Leiden University Medical Center with a GA of 24-30 weeks. In total, 23 infants were not included because the study was conflicting with other trials-the monitor was not available or consent was not given. Also, 23 infants of 2730 weeks' gestation were not included as we reached full recruitment for that stratification group.

Therefore, 30 infants were randomized. Of these, four infants were excluded because of failure to obtain recordings (one infant in the caffeine DR group and three infants in the control group), and one infant was excluded because the timing of administration of caffeine exceeded the time stated in the protocol. Two infants (one infant in each group) remained apnoeic at 7-9 min after birth, and outcome parameters could not be obtained from these infants. Therefore, 23 infants were analyzed-13 in the caffeine DR group and 10 in the control group (Figure 1). A total of 1,840 spontaneous breaths were analyzed-1,061 in the caffeine DR group and 779 in the control group. Of 23 infants included in analysis, 70\% (16/23) of parents gave informed consent retrospectively.

Infants included in the caffeine DR group had a significantly lower GA, despite randomization (Table 1). There were no differences in birth weight, gender, Apgar score at $5 \mathrm{~min}$, use of antenatal corticosteroids, mode of delivery, need for 


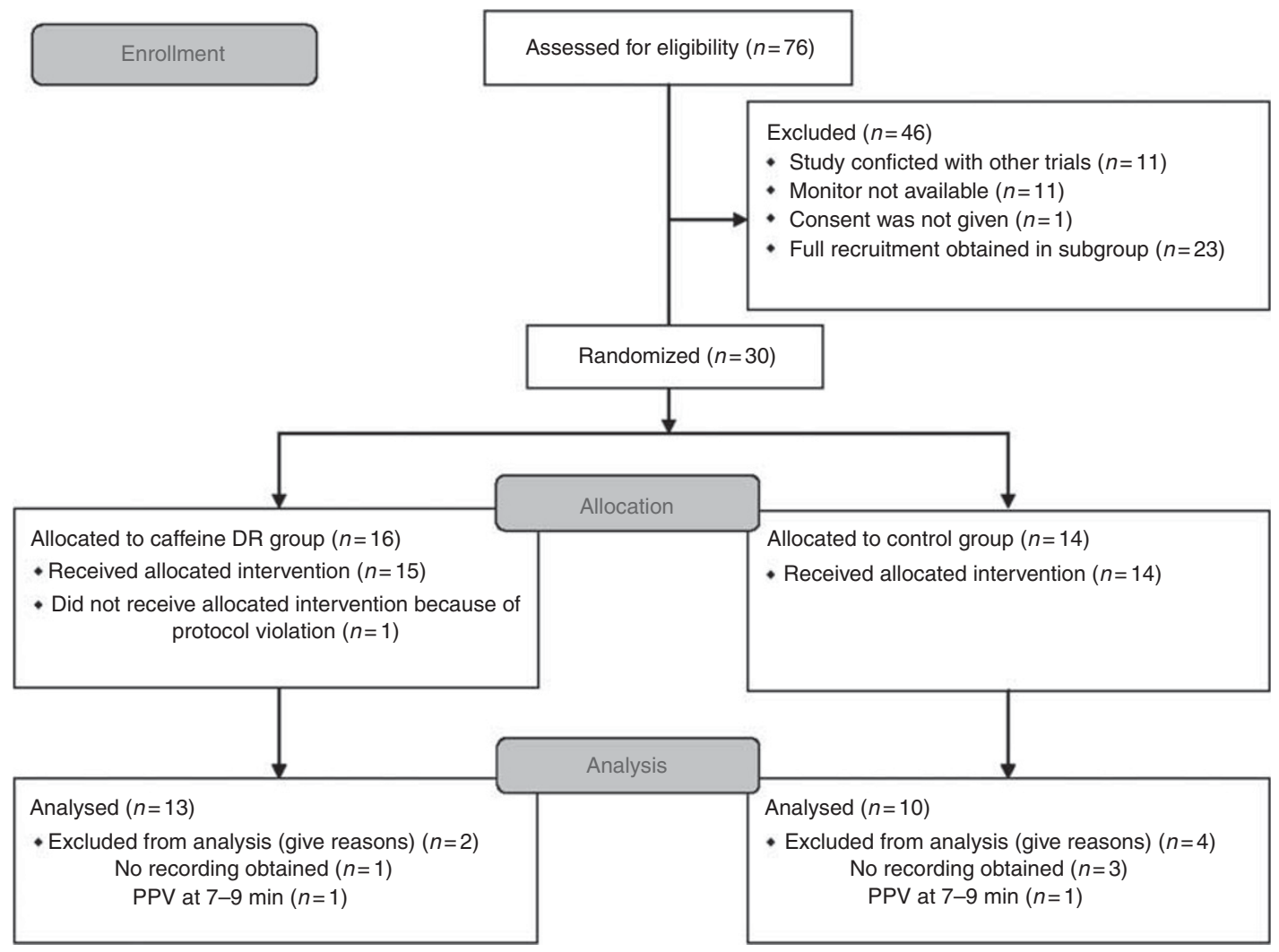

Figure 1. CONSORT 2010 flow diagram. PPV, positive pressure ventilation.

Table 1. Demographical data

\begin{tabular}{|c|c|c|c|}
\hline & Caffeine DR group & Caffeine NICU group & $P$ value \\
\hline Gestational age (weeks) $^{\mathrm{a}}$ & $27(26-28)$ & $28.5(27-29)$ & 0.049 \\
\hline Birth weight $(g)^{b}$ & $870(767-1,198)$ & $960(731-1,450)$ & NS \\
\hline Apgar score at $5 \mathrm{~min}^{\mathrm{b}}$ & $9(7-9)$ & $8(7-9)$ & NS \\
\hline Antenatal use of corticosteroids ${ }^{c}$ & $13 / 13(100 \%)$ & $10 / 10(100 \%)$ & NS \\
\hline Cord $\mathrm{pH}$ after birth ${ }^{\mathrm{b}}$ & $7.33(7.22-7.36)$ & $7.26(7.20-7.29)$ & NS \\
\hline Cord BE after birth & $-4.6 \pm 3.1$ & $-5.2 \pm 2.6$ & NS \\
\hline Intubation during NICU admission ${ }^{c}$ & $7 / 13(54 \%)$ & $4 / 10(40 \%)$ & NS \\
\hline Surfactant administration ${ }^{c}$ & $9 / 13(69 \%)$ & $5 / 10(50 \%)$ & NS \\
\hline
\end{tabular}

DR, delivery room; IQR, interquartile range; NICU, neonatal intensive care unit; NS, not significant.

${ }^{\mathrm{a}}$ Data are presented as mean \pm SD for parametric data.

${ }^{b}$ Median (IQR) for nonparametric data.

${ }^{c} n$ (\%) for categorical data.

sustained inflation, cord $\mathrm{pH}$, or Base Excess at birth. Caffeine was given at a median (interquartile range) time of 4.4 (3.65.5) min after birth in the caffeine DR group and at 48 (32.8107.3) min after birth in the control group.
Respiratory Effort at 7-9 min after Birth

At 7-9 min after birth, minute volume (MV) was significantly $(P=0.006)$ related to GA (Figure 2$)$. When corrected for GA, $\mathrm{MV}$ was significantly greater in the caffeine DR group than in 


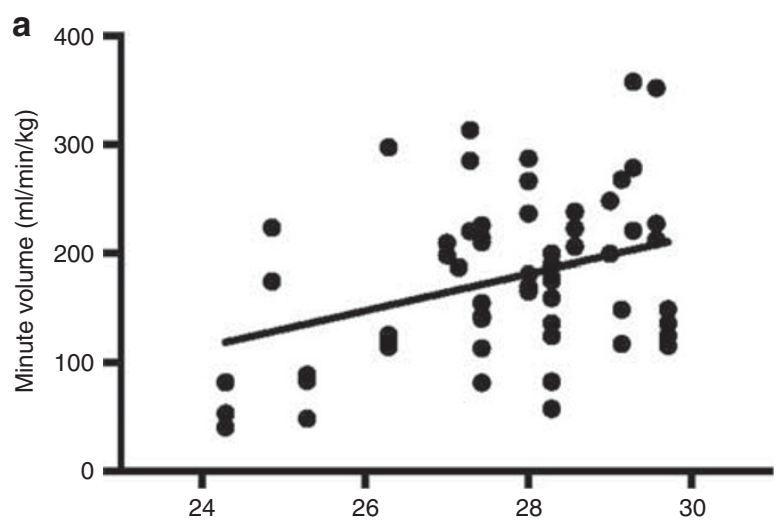

$P=0.006$

Slope $=2.4 \mathrm{ml} / \mathrm{min} / \mathrm{kg}$ per day

b

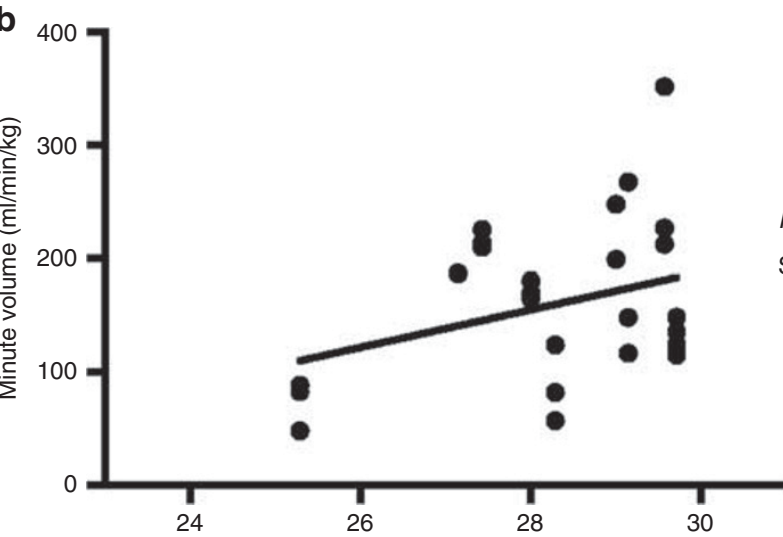

$P=0.09$

Slope $=2.3 \mathrm{ml} / \mathrm{min} / \mathrm{kg}$ per day

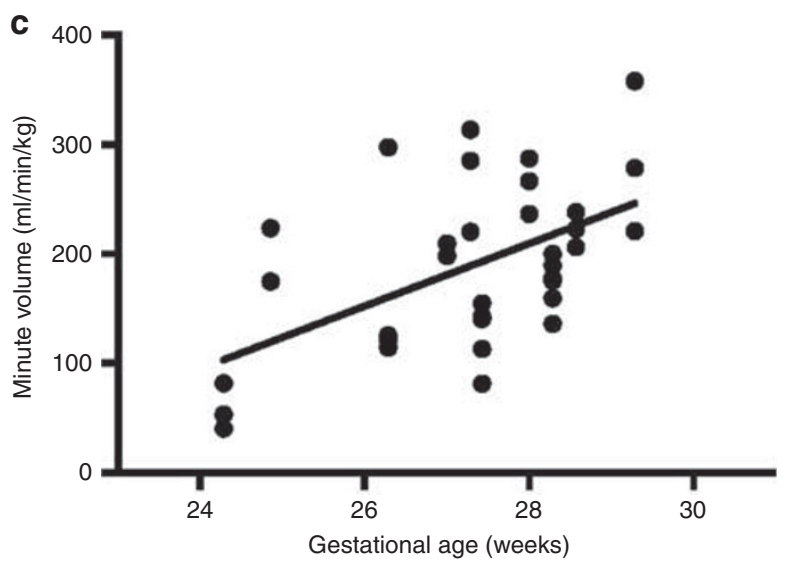

$P=0.0008$

Slope $=4.1 \mathrm{ml} / \mathrm{min} / \mathrm{kg}$ per day

Figure 2. Minute volume in relation to gestational age. Graph a: total study population. Graph b: control group. Graph c: caffeine delivery room group.

the control group $(189 \pm 74$ vs. $162 \pm 70 \mathrm{ml} / \mathrm{kg} / \mathrm{min} ; P<0.05$, odds ratio ( $95 \%$ confidence interval) $53.1(18.0-88.3)$ ). When analyzed within each group (Figure 2), the relationship between MV and GA was significant in the caffeine DR group $(P=0.0008 ;$ slope $=4.1 \mathrm{ml} / \mathrm{min} / \mathrm{kg}$ per day $)$, but not in the control group $(P=0.09$; slope $=2.3 \mathrm{ml} / \mathrm{min} / \mathrm{kg}$ per day $)$.

$\mathrm{Vt}_{\mathrm{i}}, \mathrm{RoR}$, percentage of recruitment breaths, and heart rate were significantly higher (all $P<0.001$ ) in the caffeine DR group as compared with the control group (Table 2). There were no differences in respiratory rate, maximum $\mathrm{FiO}_{2}$, and $\mathrm{SpO}_{2}$ (Table 2).

\section{Direct Effect of Caffeine}

In the caffeine DR group, both the spontaneous breathing MV $(($ mean \pm SD) $236.8 \pm 106.6$ vs. $134.8 \pm 103.9 \mathrm{ml} / \mathrm{kg} ; P<0.05$, odds ratio (95\% confidence interval) $39.2(-1.5-79.9))$ and inspired tidal volumes ((median (interquartile range)) 5.3 (3.8-8.2) vs. $4.1(2.4-7.2) \mathrm{ml} / \mathrm{kg} ; P<0.001$, odds ratio $(95 \%$ confidence interval) $1.4(0.9-1.9))$ were significantly greater in the minute after caffeine administration compared with that in the minute before caffeine administration. There were no significant differences in breathing pattern (percentage of time panting, percentage of expiratory holds) between the 


\section{Articles | Dekker et al.}

Table 2. Respiratory parameters at $7-9 \mathrm{~min}$

\begin{tabular}{|c|c|c|c|c|}
\hline & $\begin{array}{l}\text { Caffeine DR group (13 patients) } \\
\qquad N=1,091 \text { breaths }\end{array}$ & $\begin{array}{c}\text { Caffeine NICU group } \\
\text { (10 patients) } N=779 \text { breaths }\end{array}$ & $P$ value & $\begin{array}{l}\text { OR (95\% confidence } \\
\text { interval) }\end{array}$ \\
\hline Minute volume $(\mathrm{ml} / \mathrm{kg})^{\mathrm{a}}$ & $189 \pm 74$ & $162 \pm 70$ & $<0.05$ & 53.1 (18.0 to 88.3$)$ \\
\hline $\begin{array}{l}\text { Average rate of rise to maximum tidal volumes } \\
(\mathrm{ml} / \mathrm{kg} / \mathrm{s})^{\mathrm{b}}\end{array}$ & $14.3(11.2$ to 19.8$)$ & 11.2 (7.9 to 15.2$)$ & $<0.001$ & 5.5 (4.8 to 6.3$)$ \\
\hline Average inspired tidal volume $(\mathrm{ml} / \mathrm{kg})^{\mathrm{b}}$ & $5.2(3.9$ to 6.4$)$ & 4.4 (3.0 to 5.6$)$ & $<0.001$ & $0.8(0.5$ to 1.0$)$ \\
\hline $\begin{array}{l}\text { Recruitment (number of breaths with inspired } \\
\text { tidal volume } / \mathrm{kg}>8 \mathrm{ml})^{c}\end{array}$ & 142/1,061 (13\%) & $67 / 779$ (9\%) & 0.001 & 1.6 (1.2 to 2.2$)$ \\
\hline Respiratory rate/min at 7-9 min after birth ${ }^{a}$ & $35 \pm 10$ & $33 \pm 10$ & NS & $4.7(-0.5$ to 9.9$)$ \\
\hline Heart rate (b.p.m.) ${ }^{b}$ & 157 (141 to 170$)$ & $146(135-160)$ & $<0.001$ & 9.7 (8.2 to 11.2$)$ \\
\hline $\begin{array}{l}\text { Maximum fraction of inspired oxygen at } \\
7-9 \text { min after birth }{ }^{a}\end{array}$ & $0.55 \pm 0.21$ & $0.63 \pm 0.27$ & NS & $10.0(-15.7$ to 35.7$)$ \\
\hline $\begin{array}{l}\text { Fraction of inspired oxygen when leaving the } \\
\text { delivery room }\end{array}$ & $0.35(0.31$ to 0.40$)$ & $0.39(0.32$ to 0.63$)$ & NS & $7.8(-12.2$ to 27.7$)$ \\
\hline Oxygen saturation (\%) at 7-9 min after birth ${ }^{\mathrm{b}}$ & 91 (87 to 94$)$ & 91 (88 to 94$)$ & NS & $-0.2(-0.7$ to 0.4$)$ \\
\hline
\end{tabular}

Table 3. Differences in breathing patterns

\begin{tabular}{|c|c|c|c|c|}
\hline & Minute before caffeine & Minute after caffeine & $P$ value & OR (95\% confidence interval) \\
\hline Percentage of expiratory holds (\%) & $43.5 \pm 16.8$ & $43.1 \pm 28.7$ & NS & $8.0(-9.5-25.5)$ \\
\hline Percentage of time panting $(\%)^{\mathrm{b}}$ & $0(0-18)$ & $0(0-6)$ & NS & $-0.8(-7.8-6.1)$ \\
\hline
\end{tabular}

$\mathrm{IQR}$, interquartile range; $\mathrm{OR}$, odds ratio.

a Data are presented as mean \pm SD for parametric data.

${ }^{b}$ Median (IQR) for nonparametric data.

minutes before and after caffeine administration for infants receiving caffeine directly after birth (Table 3 ).

\section{Short-Term Clinical Outcomes}

There were no differences between the groups in short-term clinical outcomes. Intubation rates following NICU admission, surfactant administration, either by endotracheal tube or by minimal invasive surfactant therapy, and all grades of intraventricular hemorrhage were similar in the caffeine DR group and the control group, respectively (Table 1).

\section{DISCUSSION}

In this randomized controlled trial, we found that MV at 79 min after birth was significantly greater in the caffeine DR group than in the control group, after correction for GA. Although respiratory rate did not increase, all other parameters assessing respiratory effort increased significantly by caffeine administration, including $\mathrm{Vt}_{\mathrm{i}}, \mathrm{RoR}$, and the percentage of recruitment breaths. We also observed an immediate increase in respiratory effort in the minute after caffeine administration in caffeine-treated infants. There was a moderate but significant increase in heart rate, but oxygen need and $\mathrm{SpO}_{2}$ did not differ between the groups. These results indicate that caffeine at birth could play a role in stimulating breathing during transition at birth.
Studies have reported the effect of caffeine in preterm infants with apneas of prematurity $(13,14)$, whereas the focus of more recent studies has shifted toward the timing of the caffeine administration and its effect on breathing and ventilation (15). Our study confirmed the increase in $\mathrm{Vt}_{\mathrm{i}}$ observed in the study of Kraaijenga et al., although they did not report the immediate effect of caffeine and the infants were 1-4 days old. They observed increased diaphragmatic activity at 5 min after caffeine administration and increased $\mathrm{Vt}_{\mathrm{i}}$, measured using inductive plethysmography, in the first hour after administration (15).

Bairam et al. (19) observed a large increase in MV when caffeine was administered to 2-5-day-old term lambs with well-established respiratory rhythms. On the basis of this stimulatory effect in lambs, we expected caffeine to stimulate MV and other respiratory parameters directly after birth in preterm infants. In our study, the stimulatory effect of caffeine was clear with regard to increasing $\mathrm{RoR}, \mathrm{Vt}_{\mathrm{i}}$, and frequency of recruitment breaths. We also found a significant $(P=0.006)$ relationship between $\mathrm{MV}$ and GA in all infants at 7-9 min after birth (Figure 2). As the GA was different between the groups, despite randomization, we adjusted MV for GA. Adjusted for GA, MVs were significantly greater in caffeinetreated infants than in control infants. Furthermore, in caffeine-treated infants, we found that the relationship 
between MV and GA was highly significant $(P=0.0008)$, with $\mathrm{MV}$ increasing at a rate of $4.1 \mathrm{ml} / \mathrm{min} / \mathrm{kg}$ per day. In contrast, in control infants, the relationship between MV and GA just failed to reach statistical significance $(P=0.09)$, because of the small number of observations, with MV tending to increase at only $2.3 \mathrm{ml} / \mathrm{min} / \mathrm{kg}$ per day. These findings indicate that caffeine enhances the GA-related increase in MV, and that the stimulatory effect of caffeine on MV increases with GA.

te Pas et al. (21) described that braked expirations occur often in preterm and term infants, but expiratory holds occurred significantly more often in preterm infants. In this situation, the glottis closure combined with abdominal muscle contraction and increase in intrathoracic pressure helps to maintain functional residual capacity. In our study, the percentage of expiratory holds in the minute after caffeine administration did not differ from that in the minute before caffeine administration, but at 7-9 min after birth the percentage of expiratory holds was significantly greater in the caffeine DR group. The increase in respiratory effort observed at 7-9 min after birth might be explained by a change in breathing pattern.

Caffeine antagonizes adenosine at its receptor, and thereby stimulates the respiratory center in the medulla, and increases skeletal muscle tone, diaphragmatic contractility, and the sensitivity to carbon dioxide $(22,23)$. The levels of adenosine, however, may vary considerably in infants under different conditions, such as the mode of delivery and the presence of hypoxemia (24). Irestedt et al. (24) showed higher plasma adenosine concentrations in infants born vaginally compared with those in infants born with cesarean section, possibly due to hypoxemia caused by uterine contractions. Indeed, in piglets in the first 3 days after birth, hypoxemia can increase adenosine levels and reduce MVs (25). However, administration of aminophylline, a xanthine derivative, counteracted the effect of adenosine and increased MVs by $43.5 \%$, an effect that persisted for at least 6 min despite persisting hypoxemia (25). Therefore, the effect of caffeine may also differ at birth because of different levels of hypoxemia. It is possible that different dosages of caffeine are needed to compete with the level of adenosine present at birth or to overcome other variables.

In this study, a bolus of $1 \mathrm{ml} / \mathrm{kg}$ of caffeine, followed by a $2 \mathrm{ml}$ flush of saline, was administered in the caffeine DR group. The effect of the administration of a volume bolus on cerebral perfusion is a well-discussed subject. In the study by Kooi et al. (26), cerebral perfusion did not improve after the volume expansion $(15 \mathrm{ml} / \mathrm{kg})$ in the first day of life in infants with a GA of 25-28 weeks, although this might be caused by the presence of an adequate cerebral autoregulation. In the present study, it is not clear how the administration of the small bolus of caffeine and saline might have influenced cerebral outcomes. There are additional factors influencing these outcomes, as mentioned by Rajani et al. (27) in their review on delivery room management. The use of positive pressure ventilation and rapid $\mathrm{PaCO}_{2}$ changes influence cerebral blood flow, thereby increasing the risk of intraventricular hemorrhage. However, in our study, there were no differences between the caffeine DR group and the control group by means of any grade of intraventricular hemorrhage or periventricular leucomalacia.

This study is limited by the lack of a placebo-controlled group. It is theoretically possible that the flush of saline given, before caffeine was administered, could have a positive effect on the breathing effort. When reviewing the monitor recordings, we did not observe any effect when a flush of saline was given before the administration of caffeine; however, the caregivers were not blinded for the allocated intervention when reviewing the monitor recordings.

This study is also methodologically limited by excluding study participants, and thereby not reaching the proposed sample size. Infants were excluded because of failure of the recordings, which was only visible during analysis. Therefore, no additional infants could be included. Another methodologic limitation is the sample size calculation, which was based on the experimental data from 2-5-day-old lambs and the data from preterm infants multiple days after birth. The proposed change in $\mathrm{MV}$ of $150 \mathrm{ml} / \mathrm{kg}$ appears to be too optimistic, as the overall mean \pm SD MV in this study was $152 \pm 74 \mathrm{ml} / \mathrm{kg}$ in preterm infants during the first few minutes after birth.

In addition, infants in the caffeine DR group had a significantly lower GA. Our finding of a significant relationship between MV and GA indicates that older infants have a more developed respiratory control system. As this could have influenced the outcomes, resulting in an underestimation of the effect size, we corrected analyses for GA using multiple regression.

\section{CONCLUSION}

In this small randomized trial, we observed a direct positive effect of administering caffeine on the respiratory effort in preterm infants at birth. The results of this study provide evidence, indicating that caffeine could play a role in stimulating breathing in preterm infants during the transition. Further studies are needed to explore whether the use of caffeine in the delivery room might contribute to a decrease in delivery room intubations or additional long-term outcomes as bronchopulmonary dysplasia.

\section{STATEMENT OF FINANCIAL SUPPORT}

The Leiden University Fund (LUF) provided an unrestricted grant for the project. LUF had no role in study design; collection, analysis, and interpretation of data; writing of the report; and decision to submit the paper for publication. The authors have no financial relationships relevant to this article to disclose.

\section{Disclosure: The authors declare no conflict of interest.}

\section{REFERENCES}

1. Siew ML, Wallace MJ, Kitchen MJ, et al. Inspiration regulates the rate and temporal pattern of lung liquid clearance and lung aeration at birth. J Appl Physiol (1985) 2009;106:1888-95.

2. Hooper SB, Pearson JT, Wallace MJ, et al. Partial lung aeration causes ventilation/perfusion mismatch in the lungs at birth. Arch Dis Child 2012;97:A42. 


\section{Articles | Dekker et al.}

3. Schilleman K, van der Pot CJ, Hooper SB, Lopriore E, Walther FJ, te $\mathrm{Pas} A B$. Evaluating manual inflations and breathing during mask ventilation in preterm infants at birth. J Pediatr 2013;162:457-63.

4. van Vonderen JJ, Hooper SB, Hummler HD, Lopriore E, te Pas AB. Effects of a sustained inflation in preterm infants at birth. J Pediatr 2014;165:903-8.e1.

5. O'Donnell CP, Kamlin CO, Davis PG, Morley CJ. Crying and breathing by extremely preterm infants immediately after birth. J Pediatr 2010;156: 846-7.

6. Finer NN, Carlo WA, Walsh MC, et al. Early CPAP versus surfactant in extremely preterm infants. N Engl J Med 2010;362:1970-9.

7. Trevisanuto D, Satariano I, Doglioni N, et al. Changes over time in delivery room management of extremely low birth weight infants in Italy. Resuscitation 2014;85:1072-6.

8. Morley CJ, Davis PG, Doyle LW, et al. Nasal CPAP or intubation at birth for very preterm infants. N Engl J Med 2008;358:700-8.

9. Harding R, Bocking AD, Sigger JN. Influence of upper respiratory tract on liquid flow to and from fetal lungs. J Appl Physiol (1985) 1986;61:68-74.

10. Lee AC, Cousens S, Wall SN, et al. Neonatal resuscitation and immediate newborn assessment and stimulation for the prevention of neonatal deaths: a systematic review, meta-analysis and Delphi estimation of mortality effect. BMC Public Health 2011;11:S12.

11. Wall SN, Lee AC, Niermeyer $\mathrm{S}$, et al. Neonatal resuscitation in lowresource settings: what, who, and how to overcome challenges to scale up? Int J Gynaecol Obstet 2009;107:S47-62.

12. World Health Organization 2012 Guidelines on basic newborn resuscitation.

13. Schmidt B, Roberts RS, Davis P, et al. Caffeine therapy for apnea of prematurity. N Engl J Med 2006;354:2112-21.

14. Kreutzer K, Bassler D. Caffeine for apnea of prematurity: a neonatal success story. Neonatology 2014;105:332-6.

15. Kraaijenga JV, Hutten GJ, de Jongh FH, van Kaam AH. The Effect of Caffeine on Diaphragmatic Activity and Tidal Volume in Preterm Infants. J Pediatr 2015;167:70-5.
16. Katheria AC, Sauberan JB, Akotia D, Rich W, Durham J, Finer NN. A pilot randomized controlled trial of early versus routine caffeine in extremely premature infants. Am J Perinatol 2015;32:879-6.

17. Dobson NR, Patel RM, Smith PB, et al. Trends in caffeine use and association between clinical outcomes and timing of therapy in very low birth weight infants. J Pediatr 2014;164:992-8.e3.

18. Lodha A, Seshia M, McMillan DD, et al. Association of early caffeine administration and neonatal outcomes in very preterm neonates. JAMA Pediatr 2015;169:33-8.

19. Bairam A, Blanchard PW, Bureau MA, Laudignon N, Cote A, Aranda JV. Interactive ventilatory effects of two respiratory stimulants, caffeine and doxapram, in newborn lambs. Biol Neonate 1992;61:201-8.

20. Aranda JV, Gorman W, Bergsteinsson H, Gunn T. Efficacy of caffeine in treatment of apnea in the low-birth-weight infant. J Pediatr 1977;90: 467-72.

21. te Pas AB, Wong C, Kamlin CO, Dawson JA, Morley CJ, Davis PG. Breathing patterns in preterm and term infants immediately after birth. Pediatr Res 2009;65:352-6.

22. Aranda JV, Turmen T, Davis J, et al. Effect of caffeine on control of breathing in infantile apnea. J Pediatr 1983;103:975-8.

23. Comer AM, Perry CM, Figgitt DP. Caffeine citrate: a review of its use in apnoea of prematurity. Paediatr Drugs 2001;3:61-79.

24. Irestedt L, Dahlin I, Hertzberg T, Sollevi A, Lagercrantz H. Adenosine concentration in umbilical cord blood of newborn infants after vaginal delivery and cesarean section. Pediatr Res 1989;26:106-8.

25. Darnall RA, Bruce RD. Effects of adenosine and xanthine derivatives on breathing during acute hypoxia in the anesthetized newborn piglet. Pediatr Pulmonol 1987;3:110-6.

26. Kooi EM, van der Laan ME, Verhagen EA, Van Braeckel KN, Bos AF. Volume expansion does not alter cerebral tissue oxygen extraction in preterm infants with clinical signs of poor perfusion. Neonatology 2013;103:308-14.

27. Rajani AK, Chitkara R, Halamek LP. Delivery room management of the newborn. Pediatr Clin North Am 2009;56:515-35. 